DOI: 10.12731/2218-7405-2018-10-105-120

УДК 159.9

\title{
ПСИХОЛОГИЧЕСКИЕ ФАКТОРЫ НЕВРОТИЗАЦИИ ЮНЫХ СПОРТСМЕНОВ-ЛУЧНИКОВ
}

\author{
Нафанаилова М.С., Рыбалкина В.В.
}

Данная работа посвящена изучению факторов невротизащии юных спортсменов-лучников.

Цель. Статья посвящена актуальной в современной психологии спорта теме невротизации. Мы ставим целью выявить и описать индивидуально-психологические особенности спортсменов-лучников, препятствующих или способствующих их невротизации.

Задачи. Для достижения данной цеели потребовалось решение следуюших задач:

1. Определить уровень невротизачии спортсменов-лучников;

2. Изучить особенности самовосприятия, выраженность акцентуаций характера, уровень адаптивных способностей и способов преодоления трудностей в различных сферах психической деятельности у спортсменов-лучников;

3. Установить взаимосвязь изученных психологических характеристик с уровнем невротизации у спортсменов-лучников.

Методы проведения работы. В основу исследования легли следуюшие методики:

1. Многоуровневыйличностный опросник (МЛО) «Адаптивность», разработанный А.Г. Маклаковыли и С.В. Чермянинылм (1993).

2. УНП-уровень невротизации - клиническая тестовая методика, предназначенная для диагностики личностных черт невротического уровня, созданный И.Б. Ласко и Б.И. Тонконогий (1974).

3. Методика изучения акцентуаџий личности К. Леонгарда (модификачия С. Шмишека) (1970).

4. Копинг-тест Лазаруса, предназначенный для определения способов преодоления трудностей в различных сферах психической деятельности (1984). 
5. Проективная методика «Автопортрет» служит для выявления индивидуально типологических особенностей человека, его представлений о себе, своей внешности, личности и отношения к ней Е.С. Романова и С.Ф. Потемкина (1991).

Научная новизна результатов исследования определяется тем, что:

1. Разработан профиль стрелков из лукана основеизученных индивидуально-психологических свойств.

2. Перспективность использования полученных данных о невротизации и психопатизации спортсменов-стрелков из лука на основе учета их индивидуально-психологических свойств в учебно-тренировочном процессе.

Результаты. Вся тренировочная и соревновательная деятельность юных лучников проходят на фоне сильного эмоционального напряжения, а также в условиях постоянно усиливающейся конкуренции между спортсменами.

Так, уровень невротизации спортсменов-лучников колеблется от низкого и очень низкого значения - есть взаимосвязь с низким уровнем коммуникативных способностей. Что же касается психопатизации юных спортсменов, то их значения равны от неопределенного до пониженного уровня.

Это говорит о том, что в рамках психологической помощии юным спортсменам одним из возможных направлений работы может быть аутотренинг, тренинги на доверие, а также сплочение спортивного коллектива.

Область применения результатов. Результаты нашего исследования могут быть применимы при разработке учебных курсов для студентов-психологов, посвященных актуальным проблемам современной психологии, а также в проиессе консультирования и коррекционной работы клинических и спортивных психологов с подростками по проблемам невротизации, самовосприятия себя.

Ключевые слова: невротизация; индивидуально-психологические особенности; юноши-спортсмены; акиентуации характера. 


\section{PSYCHOLOGICAL FACTORS OF THE NEUROTIZATION OF YOUNG SPORTSMEN-ARCHERS}

\section{Nafanailova M.S., Rybalkina V.V.}

This work is devoted to the study of the neurotic factors of young athletes-archers.

Purpose. The article is devoted to the topic of neurotization that is relevant in modern psychology of sports. We aim to identify and describe the individual psychological characteristics of athletes-archers, impeding or contributing to their neuroticism.

Tasks. To achieve this goal, the following tasks were required:

1. To determine the level of neurotization athletes archers;

2. To study the peculiarities of self-perception, the severity of character accentuations, the level of adaptive abilities and ways to overcome difficulties in various spheres of mental activity in archery athletes;

3. To establish the relationship of the studied psychological characteristics with the level of neurotization in athletes-archers.

Methodology. The study was based on the following methods:

1. Multi-level personal questionnaire (MLO) "Adaptability”, developed by A.G. Maklakov and S.V. Chermyanin (1993).

2. The level of neuroticism - a clinical test method designed to diagnose personality traits of the neurotic level, created by I.B. Lasko and B.I. Tonkonogy (1974).

3. The method of studying the accentuations of the personality of K. Leongard (modification of S. Shmishek) (1970).

4. Lazarus copying test designed to determine how to overcome difficulties in various spheres of mental activity (1984).

5. The projective technique of "Self-portrait" serves to identify individually typological features of a person, his ideas about himself, his appearance, personality, and attitude to it by E.S. Romanov and S.P. Potemkin (1991).

The scientific novelty of the research results is determined by the fact that: 
1. Developed a profile of archers on the basis of the studied individual psychological properties.

2. The prospect of using the data obtained on the neurotic and psychopathization of the athletes-archers from the bow on the basis of taking into account their individual psychological properties in the training process.

Results. All training and competitive activities of young archers take place against the background of strong emotional stress, as well as in the conditions of constantly increasing competition between athletes.

Thus, the level of neurotization of archery athletes ranges from low and very low values - there is an interrelation with a low level of communicative abilities. As for the psychopathization of young athletes, their values are equal from undetermined to reduced levels.

This suggests that within the framework of psychological assistance to young athletes, one of the possible areas of work may be auto-training, trust training, and rallying of a sports team.

Practical implications. The results of our study may be applicable in the development of training courses for psychology students on current problems of modern psychology, as well as in the process of counseling and remedial work of clinical and sports psychologists with adolescents on the problems of neuroticism, self-perception.

Keywords: neuroticism; individual psychological characteristics; young athletes; character accentuation.

В спортивной психологии существует достаточно много данных, которые свидетельствуют о необходимости психологической подготовки и ее влиянии на результативность соревновательной деятельности.

В современном мире значительное распространение неврозов и наблюдающееся стремление к их росту требует более углубленного изучения закономерностей в системе отношений и выявления преобладающих разновидностей внутриличностных конфликтов. В ряде случаев невроз у спортсменов развивается вследствие значительной нервно-психической перегрузки, но также несомненную роль 
играют как физиологические особенности организма, так и индивидуально-личностные факторы.

Исследования, проводимые в стрельбе, показывают, что необходимым для стрелка является адекватное оценивание своих ощущений, полное управление своими действиями, четкий план действий. Соревнования проходят на фоне сильного эмоционального напряжения, а также в условиях постоянно усиливающейся конкуренции между спортсменами. Следовательно, изучение невротизации юных спортсменов-лучников важно для повышения успешности в спортивной деятельности, индивидуализации процесса подготовки спортсменов, а также для улучшения адаптации спортсмена.

Соревнования между стрелками из лука ведется на пределах возможностей, так как основное противоборство ведется в области психологической составляющей. В настоящее время вопросы психологической подготовки спортсменов в стрельбе не разрешены до конца, и поэтому они составляют проблему нашего исследования, так как сейчас неудачи спортсмена на соревнованиях объясняют пробелами его психологической подготовки.

Таким образом, актуальность изучения факторов невротизации юных спортсменов-лучников обусловлена возможностью использовать ее материалы в профессиональной деятельности клинического и спортивного психолога, а также открыть возможности для составления программы направленной на коррекцию неблагоприятных проявлений.

Повседневная жизнь дает многочисленные примеры того, что тяжелые переживания, потрясения, постоянные стрессы нередко вызывают нервные расстройства. Такие стойкие расстройства, возникающие в результате нервного перенапряжения и истощения, называются неврозами.

Термин «невроз» в 1776 году ввел шотландский врач Уильям Куллен. Автор объединил понятием невроз широкий круг страданий, которые зависели только от нарушения деятельности нервной системы. Данным термином долгое время практически пользовались лишь врачи. 
Большой прогресс таких наук как психиатрия и неврология привели к большому совершенствованию клинической диагностики, что и послужило причиной исключения из группы неврозов большинства соматических, нервных и психических заболеваний.

Но есть люди, у которых отклонения личности настолько выражены, что они сами страдают от своей анормальности, или от нее страдают окружающие. Носителей такого характера называют психопатами.

Психопатия - врожденная или развившаясяаномалия личности (аномальность высшей нервной деятельности), обусловливающая психическую неполноценность личности.

Психопатический склад личности возникает на основе взаимодействия врожденной или рано приобретенной биологической неполноценности нервной системы с остро негативными условиями внешней среды. Характерологической особенностью психопатизированной личности является дисгармоничность ее эмоционально-волевой сферы при относительной сохранности интеллекта. Психопатические особенности личности затрудняют ее социальную адаптацию, а при психотравмирующих обстоятельствах ведут к дезадаптивным поведенческим актам.

Невротические расстройства и психопатические нарушения носят взаимоисключающий характер. Различия заключаются в следующем:

- Для неврозов наследственность не значима, а для психопатий играет определяющую роль;

- При неврозах, в отличие от психопатий, отсутствуют расторможенность, конфликтность в сочетании с агрессивностью и жестокостью, выражено чувство вины, стыда, сочувствие, переживание случившегося, осознание своей болезни;

- Неврозы обратимы в результате благоприятного изменения обстоятельств или лечения;

- При неврозах, в отличие от психопатий, отношение к лечению положительное, ребенок ищет помощи, стремится избавиться от страданий.

Что же касается факторов, которые могут поспособствовать повышению чувствительности к психотравматизирующим влияниям в 
спорте достаточно много. В первую очередь следует выделить психическую установку человека при ожидании события, которое эмоционально довольно значимо для него; его астенические состояния, которые возникают в связи с перенапряжением, переутомлением и недосыпанием; а также нахождение в незнакомой для спортсмена обстановке. Главную роль здесь играют преморбидные особенности личности, в том числе носящие психопатологический характер, а также конституционально обусловленная чувствительность.

Неврозы у спортсменов развиваются довольно медленно и постепенно, поэтому при первых симптомах нужно сразу же полностью вносить подходящие коррективы в весь тренировочный процесс. Данные коррективы могут выражаться понижении привычной нагрузки, и плюс во внедрении дополнительного отдыха для спортсмена; также возможно дополнительное введение каких-нибудь развлекательных мероприятий и т. д.

Для спортсмена важно соблюдать режим дня, достаточно высыпаться, придерживаться строгого режима, а также полноценно питаться и исключение различные вредные привычки.

Если брать перетренированность у спортсменов, то она встречается повсеместно и довольно часто. Что касается определения термина перетренированности, то это такое патологическое состояние, которое развивается вследствие постоянного хронического физического напряжения, а клиническую картину здесь составляют множественные функциональные нарушения в центральной нервной системе.

В корне данной болезни лежит перенапряжение тормозного и возбудительного процессов, а также их подвижности в коре больших полушарий головного мозга. Все вышеперечисленное позволяет отнести патогенез перетренированности спортсменов к процессу неврозов.

Обратимся к результатам исследования.

Исследование проводилось в 2016-2017 учебном году институтом психологии СВФУ в Республиканском училище олимпийского резерва им. Р.М. Дмитриева среди обучающихся 8-11 классов.

Выборка составила 60 человек из них 30 юношей, занимающихся стрельбой из лука и 30 юношей, занимающихся пулевой стрельбой. 
Для того, чтобы выявить уровень невротизации или психопатизации спортсменов-лучников мы использовали клиническую тестовую методику «Уровень невротизации и психопатизации», предложенную И.Б. Ласко и Б.И. Тонконогим.

В ходе анализа полученных данных мы получили следующие результаты. Большинство испытуемых имеет низкий и очень низкий уровень невротизации, а также неопределенный и пониженный уровень психопатизации.

При низком уровне невротизации у испытуемых может отмечаться эмоциональная устойчивость и положительный фон основных переживаний (спокойствие, оптимизм). Но у спортсменов, занимающихся стрельбой из лука замечена некоторая отгороженность

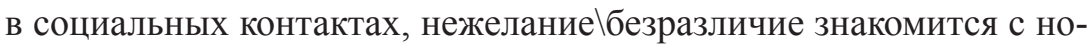
выми людьми.

При неопределенном уровне психопатизации можно говорить о некоторой беспечности и легкомыслии, а также холодном отношении к людям. В некоторых случаях может проявляться осмотрительность, уступчивость, ориентированность на мнение окружающих; приверженность к соблюдению общепринятых правил норм и поведения.

Исследовав невротизацию и психопатизацию спортсменов, занимающихся пулевой стрельбой мы пришли к следующим выводам.

У спортсменов-винтовочников уровень невротизации находится на уровне от неопределенного до низкого. Испытуемые довольно оптимистичны, общительны, в контакт вступают с легкостью. Также им присуща независимость, легкость в общении, но здесь могут возникнуть проблемы во взаимоотношениях, взаимопонимании (особенно у тренера, когда необходимо держать дисциплину).

Психопатизация колеблется от пониженного до среднего уровня, хотя она связана с рядом личностных особенностей юных спортсменов: низкий уровень планирования решения проблемы и гипертимность акцентуации. Лицам с таким типом присуще упрямство в межличностных взаимоотношениях. 


\section{Взаимосвязь индивидуально-психологических особенностей} с уровнем невротизации у спортсменов-лучников. Личность каждого человека, в том числе и спортсмена, наделена только ей присущим сочетанием психологических черт и особенностей, образующих ее индивидуальность, составляющих ее своеобразие, отличие от других людей.

На основе вышепредставленного материала мы выдвинули гипотезу о том, что уровень невротизации спортсменов-лучников зависит от ряда индивидуально-психологических свойств личности.

Первый этап нашего исследования был направлен на определение того, какими способами спортсмены преодолевают трудности в различных сферах психической деятельности. Для решения данной задачи мы использовали методику копинг-тест Лазаруса.

Высокие результаты, свидетельствующие о выраженной дезадаптации, были набраны по следующим субшкалам: Планирование решения проблемы и Положительная переоценка. Это может говорить о том, что испытуемые редко \не преодолевают проблемы за счет целенаправленного анализа ситуации и собственного поведения, не вырабатывают стратегии разрешения проблемы, не используют прошлый опыт и имеющиеся ресурсы.

Что же касается спортсменов, занимающихся пулевой стрельбой, то испытуемые в основном набрали средний результат по всем шкалам. Это говорит о том, что адаптационный потенциал личности находится в пограничном состоянии. Также в ходе выполнения статистического анализа мы выяснили, что у испытуемых существует корреляционная связь между высоким уровнем невротизации и высоким уровнем конфронтационного копинга. Это говорит о том, что испытуемые не всегда имеют способность к сопротивлению различного рода трудностям.Испытуемые не хотят или не умеют отстаивать собственные интересы. Все это в совокупности приводит к невротизации.

Также у испытуемых была выявлена корреляционная связь между повышенным уровнем психопатизации и низким уровнем планирования решения проблемы. Можно предположить, что если 
юноши не разрешают собственные проблемы с учетом прошлого опыта,товелика вероятность возникновения холодности по отношению к людям, упрямство в межличностных взаимодействиях, все это приводящее к конфликтным ситуациям.

Следующий шаг нашего исследования был направлен на то, чтобы оценить адаптационные возможности личности спортсмена с учетом социально-психологических и некоторых психофизиологических характеристик, отражающих обобщенные особенности нервно-психического и социального развития.

По шкале «Личностный адаптивный потенциал»у большинства испытуемых низкий результат: лица этой группы обладают признаками явных акцентуаций характера и некоторыми признаками психопатий, а психическое состояние можно охарактеризовать, как пограничное. Возможны нервно-психические срывы.

По шкале «Нервно-психическая устойчивость»: высокий уровень нервно-психической устойчивости и поведенческой регуляции, высокая адекватная самооценка и реальное восприятие действительности.

По шкале «Коммуникативные способности» большинство испытуемых набрали средний уровень развития коммуникативных способностей. При необходимости могут устанавливать контакт с окружающими людьми.

По шкале «Моральная нормативность»: высокий уровень - испытуемые могут реально оценить свою роль в коллективе, соблюдать общепринятые нормы поведения.

С помощью проверки ранговой корреляции Спирмена была обнаружена корреляционная связь между низким уровнем коммуникативныхспособностей и повышенным уровнем невротизации.

Для спортсменов является важным общение, коммуникация с тренером, товарищами по команде, соперниками и т.д. Но так как стрельба из лука - это единоличный вид спорта, то мы можем предположить, что общение для спортсменов лучников является тяжелым и вынужденным (по мере необходимости). Так, в ходе личной беседы с каждым спортсменом мы заметили, что они держатся отгорожено, говорят односложно и без особых эмоций. Следователь- 
но, можно сделать вывод о том, что общение для этих спортсменов связано с невротизацией.

Такой вывод нам позволяет сделать непараметрический критерий ранговой корреляции Спирмена. Данная корреляция статистически значима 0,694 при $\mathrm{N}=0,01$.

Если брать во внимание данные спортсменов, занимающихся пулевой стрельбой, то по всем шкалам испытуемые набрали высокие результаты, из этого следует, что всем испытуемым присуща адекватная самооценка, реальное оценивание своей роли в коллективе, а также высокое умение устанавливать контакты.

Третьим этапом нашего исследования явилось выявление тех или иных типов акцентуаций по методике К. Леонгарда. Так мы выяснили, что большинство испытуемых не испытывают явные признаки акцентуаций личности, но примерно четверть из них имеют среднюю степень выраженности акцентуаций личности по таким шкалам, как гипертимность, циклотимичность, неуравновешенность и аффективность.

Из общения с испытуемыми мы заметили, что им свойственна некоторая грубость, гневливость (особенно, если предложенное тестовое задание не нравилось), склонность к конфликтам. Так при заполнении некоторых методик испытуемые подшучивали друг над другом, выставляя своего напарника в «худшем свете».

Взаимосвязи между невротизацией и акцентуациями личности спортсменов с помощью ранговой корреляции Спирмена обнаружить не удалось.

Изучив наличие акцентуированных черт у спортсменов, занимающихся пулевой стрельбой мы получили следующие результаты. По шкалам застревание и ригидность испытуемые набрали средние результаты. Также обнаружена корреляционная связь между повышенным уровнем психопатизации и гипертимностью. Мы можем выдвинуть предположение, что, так как людям данного типа присуща подвижность, общительность, напористость, то такая большая импульсивность может служить источником конфликтов, особенно, если на пути им встречается противодействие. Чрезмерная само- 
стоятельность и упорство приводят к тому, что люди данного типа плохо переносят жесткую дисциплину и как следствие это у них вызывает высокий уровень психопатизации.

На заключительном этапе мы использовали проективную методику «Автопортрет», которая помогла выявить индивидуально-типологические особенности личности, его представления о себе, своей внешности. Большинство испытуемых изображает себя в виде схематичного рисунка в полный рост. В основном рисунок изображен в большом формате, посередине страницы. Что касается идентификации, то она не совсем адекватная, то есть не соответствует возрасту респондента. Направленность рисунка - открытая.

В основном все спортсмены не желали изображать себя, ссылаясь на неумение рисовать, стеснение, незнание своей внешности с стороны.

Достоверность данных о том, что большинство спортсменов изображают себя в виде сюжетного изображения, позволяет проверить непараметрический критерий Манна-Уитни. Данное различие статистически значимо U крит. $=0,047$ при $\mathrm{P} \leq 0,5$.

Проанализировав взаимосвязь между уровнем невротизации с рядом индивидуально-психологических особенностей спортсменов, занимающихся стрельбой из лука в возрасте от 14 до 18 лет мы пришли к следующим выводам.

Были обнаружены статистически значимые различия в уровне невротизации и психопатизации между исследуемыми лучниками и винтовочниками.

Так, уровень невротизации спортсменов-лучников колеблется от низкого и очень низкого значения, хотя она взаимосвязана с низким уровнем коммуникативных способностей. Что же касается психопатизации юных спортсменов, то их значения равны от неопределенного до пониженного уровня.

У спортсменов-винтовочников уровень невротизации находится на уровне от неопределенного до низкого. Психопатизация следует от пониженного до среднего уровня, хотя она связана с рядом личностных особенностей юных спортсменов: низкий уровень планирования решения проблемы и гипертимность акцентуации. 
Также были установлены некоторые параметры личностных характеристик спортсменов:

Спортсмены-лучники преимущественно интровертированы, ригидны, необщительны, склонны к грубости и агрессии в некоторых жизненных ситуациях.

Спортсмены, занимающиеся пулевой стрельбой характеризуются экстравертированностью, напористостью, общительностью и упорством.

Предположение о том, что невротизация юных спортсменовлучников связаня с рядом индивидуально-личностных особенностей не подтвердилась.

В спортивной психологии существует достаточно много данных, которые свидетельствуют о необходимости психологической подготовки и ее влиянии на результативность соревновательной деятельности.

Невроз в современном мире достаточно распространен и наблюдающееся стремление к его росту требует более углубленного изучения закономерностей в системе отношений и выявления преобладающих разновидностей внутриличностных конфликтов.

В ряде случаев невроз у спортсменов развивается вследствие сильной нервно-психической перегрузки, но также несомненную роль играют как физиологические особенности организма, так и индивидуально-личностные факторы.

Вся тренировочная и соревновательная деятельность проходят на фоне сильного эмоционального напряжения, а также в условиях постоянно усиливающейся конкуренции между спортсменами.

Таким образом, полученные в нашем исследовании данные свидетельствуют о незначительном уровне невротизации юных спортсменов, которые в ряде случаев связаны с индивидуально-личностными особенностями. Это говорит о том, что в рамках психологической помощи юным спортсменам одним из возможных направлений работы может быть аутотренинг, тренинги на доверие, а также сплочение спортивного коллектива.

Тем не менее, анализ, проделанный в рамках нашего исследования, позволяет определить основные мишени воздействия при работе с юными спортсменами, занимающихся стрелковыми вида- 
ми спорта для использования их в тренинговой, консультативной и коррекционной работе.

\section{Список литературы}

1. Алексеев А.В. Об оптимальном боевом состоянии спортсменов // Проблемы психологии спорта. М., 1971. С. 62-67.

2. Вайнштейн Л.М. Пулевая стрельба. М.: Физкультура и спорт, 1964. C. 28-54.

3. Вайнштейн Л.М. Стрелок и тренер. М.: Физкультура и спорт, 1969. 247 c.

4. Вайнштейн Л.М. Психология в пулевой стрельбе. М.: ДОСААФ, 1981. $142 \mathrm{c}$.

5. Жгутов О.М. Мастерство стрелка. М.: ДОСААФ, 1958.

6. Жилина М.Я. Исследование техники спортивной стрельбы из пистолета и методика ее совершенствования с помощью средств срочной информации : Канд. пед. наук : 13.00.04; ВНИИФК. М., 2007. 181 с.

7. Захаров А.И. Неврозы у детей и подростков. М.,1988. 246 с.

8. Иткис М.А. Оценка степени устойчивости системы «стрелок-оружие» как один из факторов для отбора стрелков // Теория и практика физ. культуры. 1969. № 6. С. 27-30.

9. Кубланов М.М. Некоторые аспекты психологической подготовки стрелков на современном этапе: методические рекомендации. Воронеж, 1999. 34 с.

10. Кутин В.П. Лечение неврозов и психозов. М., 1978. 184 с.

11. Меерсон Ф.3., Пшенникова М.Г. Адаптация к стрессовым ситуациям и физическим нагрузкам. М.: Медицина, 1988.

12. Юрьев А.А. Спортивная стрельба из винтовки. М.:ФиС, 1957.456 с.

\section{References}

1. Alekseev A.V. Problemy psikhologii sporta [Problems of the psychology of sports]. M., 1971, pp. 62-67.

2. Vaynshteyn L.M. Pulevaya strel'ba [Bullet shooting]. M.: Fizkul'turai sport, 1964, pp. 28-54.

3. Vaynshteyn L.M. Strelok i trener [Shooter and trainer]. M.: Fizkul'turai sport, 1969. $247 \mathrm{~s}$. 
4. Vaynshteyn L.M. Psikhologiya v pulevoystrel'be [Psychology in bullet shooting]. M.: DOSAAF, 1981. $142 \mathrm{p}$.

5. Zhgutov O.M. Masterstvo strelka [Skill shooter]. M.: DOSAAF, 1958.

6. ZhilinaM.Ya. Issledovanie tekhniki sportivnoy strel'by iz pistoleta i metodika ee sovershenstvovaniya s pomoshch'yu sredstv srochnoy informatsii [Investigation of the technique of sports pistol shooting and the method of its improvement using the means of urgent information]. M., 2007. $181 \mathrm{p}$.

7. Zakharov A.I. Nevrozy u deteyipodrostkov [Neurosis in children and adolescents]. M.,1988. 246p.

8. Itkis M.A. Teoriya i praktika fiz. kul'tury. 1969. № 6, pp. 27-30.

9. Kublanov M.M. Nekotorye aspekty psikhologicheskoy podgotovki strelkov na sovremennom etape: metodicheskie rekomendatsii [Some aspects of the psychological training of shooters at the present stage]. Voronezh, 1999. 34 p.

10. Kutin V.P. Lechenie nevrozov i psikhozov [Treatment of neurosis and psychosis]. M.,1978. 184 p.

11. Meerson F.Z., Pshennikova M.G. Adaptatsiya k stressovym situatsiyam i fizicheskim nagruzkam [Adaptation to stressful situations and physical activities]. M.: Meditsina, 1988.

12. Yur'ev A.A. Sportivnaya strel 'ba iz vintovki [Shooting with a rifle]. M.: FiS, 1957. 456 p.

\section{ДАННЫЕ ОБ АВТОРАХ}

Нафанаилова Мария Семеновна, кандидат психологических наук, доцент

Северо-Восточный федеральный университет ул. Белинского, 58, г. Якутск, Республика Саха (Якутия), 677000, Российская Федераичи nafagnka@mail.ru

\section{Рыбалкина Валентина Викторовна, студент}

Северо-Восточный федеральный университет ул. Белинского, 58, г. Якутск, Республика Саха (Якутия), 677000, Российская Федерачия puma05.8@mail.ru 


\section{DATA ABOUT THE AUTHORS}

Nafanailova Maria Semenovna, Ph.D. in psychology, docent

North-Eastern Federal University named after M.K. Ammosov 58, BelinskyStr., Yakutsk, Sakha Republic (Yakutia), 677000, Russian Federation

nafagnka@mail.ru

Rybalkina Valentina Viktorovna, Student of North-Eastern Federal University

North-Eastern Federal University named after M.K. Ammosov 58, BelinskyStr., Yakutsk, Sakha Republic (Yakutia), 677000, Russian Federation

puma05.8@mail.ru 